dụng trực tiếp đến hệ thần kinh trung ương lên các mẫu cần sa, khiến người sử dụng không thể ước lượng được liều lượng sử dụng, gây nhiều rủi ro nguy hiểm cho người sử dụng khi tăng liêu. Đây cũng chính là một trong những nguyên nhân dẫn đến tình trạng bị ngộ độc sau khi sử dụng cần sa tổng hợp ở các nước trên thế giới và đặc biệt là ở Việt Nam.

\section{KẾT LUẬN}

Nghiên cứu đã thành công trong việc xây dựng được một quy trình định lượng 5-FLUOROMDMB-PICA trong mẫu cỏ Mỹ bằng phương pháp GC-MS và quy trình được thẩm định đạt tất cả các yêu câu theo hướng dẫn của ICH. Lần đầu tiên tại Việt Nam xây dựng quy trình định lượng này. Ửng dụng trên 20 mẩu thực tế cho kết quả hàm lượng trung bình 5-FLUORO-MDMB-PICA được các đối tượng tẩm vào trung bình là $2,2 \mathrm{mg}$ trong $100 \mathrm{mg}$ cỏ Mỹ $(2,2 \%)$. Đảm bảoquy trình xử lý mẫu đơn giản, hiệu quả, chính xác, độ đúng và độ tin cậy cao, đạt được yêu cầu cấp thiết góp phần đảm bảo cho công tác giám định ma túy ngày càng nâng cao và quy chuẩn cho các phòng thí nghiệm giám định về ma túy ở các địa phương trên cả nước.

\section{TÀI LIÊU THAM KHẢO}

1. Chính Phủ (2020), Nghị đinh số $60 / 2020 / N D-C P$ ngày 29/05/2020 vể sứa đổi, bổ sung danh mục các chất ma túy và tiền chất

2. Truver Michael T, Watanabe Shimpei, ÅstrandAnna, Vikingsson Svante, Green
Henrik, Swortwood Madeleine J, et al. (2020) "5F-MDMB-PICA metabolite identification and cannabinoid receptor activity". Drug Testing and Analysis, 12 (1), pp 127-135.

3. Krotulski Alex J, Mohr Amanda LA, Logan Barry K (2020) "Emerging synthetic cannabinoids: development and validation of a novel liquid chromatography quadrupole time-offlight mass spectrometry assay for real-time detection". Journal of Analytical Toxicology, 44 (3), pp 207-217.

4. Mogler Lukas, Franz Florian, Rentsch Daniel, Angerer Verena, Weinfurtner Georg, Longworth Mitchell, et al. (2018) "Detection of the recently emerged synthetic cannabinoid 5FMDMB-PICA in 'legal high'products and human urine samples". Drug testing and analysis, 10 (1), pp 196-205.

5. Risseeuw Martijn DP, Blanckaert Peter, Coopman Vera, Van Quekelberghe Stijn, Van Calenbergh Serge, Cordonnier Jan (2017) "Identification of a new tert-leucinate class synthetic cannabinoid in powder and "spice-like" herbal incenses: methyl 2-[[1-(5-fluoropentyl) indole-3-carbonyl] amino]-3, 3-dimethyl-butanoate (5F-MDMB-PICA)". Forensic science international, 273, pp 45-52.

6. International Conference on Harmonisation of Technical Requirements for Registration of Pharmaceuticals for Human Use (2003), Stability Testing of New Drug Substances and Products, pp. 1-13.

7. International Conference on Harmonisation of Technical Requirements for Registration of Pharmaceuticals for Human Use (2005), Validation of Analytical procedures: Text and methodology Q2(R1), pp. 1 - 13 .

8. World Health Organization (2019) "Critical Review Report: 5F-MDMB-PICA".

\title{
NGHIÊN CỨU ĐĂC ĐIỂM LÂM SÀNG, TÝP HUMAN PAPILLOMA VIRUS VÀ KẾT QUẢ ĐIỀU TRI BÊ̂NH SÙI MÀO GÀ TAI BỆHH VIỆN DA LIỄU THÀNH PHỐ CẦN THO' NĂM 2020
}

Lạc Thị Kim Ngân*, Huỳnh Văn Bá*, Trần Gia Hưng*, Nguyễn Hoàng Khiêm*

\section{TÓM TẮT}

Mục tiêu: Mô tả đặc điểm lâm sàng, xác định týp Human papilloma virus của bệnh nhân sùi mào gà tại Bênh viên Da liễu Thành phổ Cần Thơ năm 2020 và đánh giá kết quả điều trị bệnh sùi mào gà tại Bệnh viện Da liễu Thành phố Cần Thơ năm 2020. Phướng pháp: Mô tả cắt ngang. Kết quả: Nghiên cứu 85

*Trường Đại học Y Dước Cần Thơ

Chịu trách nhiệm chính: Huỳnh Văn Bá

Email:bs.ba_fob@yahoo.com.vn

Ngày nhận bài: 29/7/2021

Ngày phản biên khoa hoc: 26/8/2021

Ngày duyệt bài: 18/9/2021 bệnh nhân có dạng thương tổn sùi mào gà nhọn $89,4 \%$, sùi mào gà sẩn $22,4 \%$, sẩn sừng hóa $5,9 \%$ và sẩn dẹt $3,5 \%$. HPV týp 6 và 11 chiếm tỷ lệ cao nhất, lần lượt là $45,9 \%$ và $54,1 \%$. Týp HPV nguy cơ thấp chiếm $18,8 \%$, nguy cơ cao chiếm $10,6 \%$ và nhiếm cả 2 nhóm týp chiếm 70,6\%. Kết quả điều trị tốt 71,8\% tỷ lệ tái phát $15,3 \%$, tỷ lệ tác dụng phụ $2,4 \%$, tỷ lế biến chứng chảy máu $1,2 \%$, đau $7,1 \%$, phù nề $8,2 \%$ và nhiễm trùng là 3,5\%. Kết luận: Sùi mào gà dạng nhon là dang thường găp nhất chiếm $89,4 \%$. HPV týp 11 là týp thường gặp nhất chiếm tỷ lệ $54,1 \%$. Kết quả điều tri tốt chiếm tỳ lê $71,8 \%$.

Tư khóa: Sùi mào gà sinh dục, Human papilloma virus. 


\section{SUMMARY}

\section{THE STUDY OF CLINICAL FEATURES, HUMAN PAPILLOMAVIRUS TYPE AND RESULT OF TREAMENT GENTIAL WART PATIENTS AT CAN THO HOSPITAL OF DERMATO-VENEREOLOGY IN 2020}

Ojectives: To describe features, identify Human papilloma virus type of genital warts patients who are treated in 2020 at Can Tho hospital of dermatovenereology. To comment about treatment results of genital warts patients in 2020 at Can Tho hospital of dermato-venereology. Methods: Cross-sectional descriptive study. Results: Among 85 genital warts patients were devided into four groups including acuminated condyloma $(89,4 \%)$, papular condyloma $(22,4 \%)$, keratotic condyloma (5,9\%) and flat-topped papules (3,5\%). HPV 6 and 11 were the most common strains associated with genital warts and were approximately $45,9 \%$ and $54,1 \%$. Low risk strains of HPV accounts for $18.8 \%$, Hight risk strains of HPV accounts for $10,6 \%$ and both types were approximately $70,6 \%$. The good result was $71,8 \%$, relapse $15,3 \%$, side effects $2,4 \%$, hemorrhage complication $1,2 \%$, pain $7,1 \%$, swelling $8,2 \%$ and infection 3,5\%. Conclusion: Acuminated condyloma was the most common clinical form which was approximately $89.4 \%$. HPV type 11 is the most common type, accounting for $54,1 \%$. The good result was $71,8 \%$.

Key word: Gential warts, Human papilloma virus

\section{I. ĐẠT VẤN ĐỀ}

Sùi mào gà sinh dục là một bệnh chiếm tỷ lệ cao nhất trong những bệnh lầy truyền qua đường tình dục, do tác nhân Human papilloma virus. Những nghiên cứu gần đây cho thấy việc nhiễm Human papilloma virus là rất phổ biến ở người trẻ trong đô tuổi hoat đông tình dục, nhưng thường không có triệu chứng và thoáng qua. Người ta ước tính rằng $30 \%$ đến $50 \%$ người lớn hoạt động tình dục bị nhiễm Human papilloma virus, chỉ có khoảng $1 \%$ đến $2 \%$ số bệnh nhân nhiếm Human papilloma virus có triệu chứng lâm sàng.

Đến nay người ta đã xác nhận có hơn 130 týp Human papilloma virus và hầu hết các týp này đều không gây ra các triệu chứng đáng chú ý và sẽ tự sạch nhiễm. Có hơn 100 týp Human papilloma virus được biết đến, trong đó týp 6 và 11 chiếm tới $90 \%$. Các týp 16, 18, 31, 33, 34 và 35 có thể gây loạn sản thượng bì và dấn đến ung thư về sau. Bệnh sùi mào gà ảnh hưởng nhiều đến chất lượng cuộc sống, gây tâm lý lo lắng và sự gánh nặng về chi phí điều trị, ước tính khoảng 6 tỷ đô la mối năm tại Hoa Kỳ. Vì thế cần có sự quan tâm, theo dõi đúng mức từ việc phòng chống lây nhiễm đến việc tầm soát phát hiện bệnh và những điều trị thích hợp, để tránh những hậu quả nặng nề về sau. Điều trị sùi mào gà có nhiều phương pháp, nhưng chưa có phương pháp nào được xem là lý tưởng[1].

\section{II. ĐỐI TƯỢNG VÀ PHƯƠNG PHÁP NGHIÊN CỨU}

1. Đối tượng nghiên cứu. Tất cả bệnh nhân được chẩn đoán sùi mào gà, được định týp Human papilloma virus và điều trị tại Bệnh viện Da liễu Thành phố Cần Thơ từ tháng 5/2020 đển tháng 11/2020. Bệnh nhân đồng ý tham gia nghiên cứu.

\section{Phương pháp nghiên cứu}

2.1. Thiết kế nghiến cứu: Mô tả cắt ngang

2.2. Cỡ mẫu: Dựa vào công thức tính cõ mầu, chọn $p=0,7$ theo Nguyễn Qúy Thái [4], tính được $n=81$. Thực tế chúng tôi chọn được 85 mẫu.

2.3. Phương pháp phân tích và xử lý số liệu. Số liệu được nhập, phân tích và xử lý bằng phần mềm SPSS 18.0

\section{KẾT QUẢ NGHIÊN CỨU}

Tuổi khởi phát bệnh nhỏ nhất trong nhóm đối tượng tham gia nghiên cứu là 18 tuổi, lớn nhất là 65 tuổi. Đa số bệnh nhân vào viện vì nổi sùi ở bộ phận sinh dục $(91,8 \%)$, phần còn lại do ngứa và̀ tình cờ phát hiện qua khám sức khỏe.

Dạng thương tổn: sùi mào gà nhọn $89,4 \%$, sùi mào gà sẩn $22,4 \%$, sẩn sừng hóa $5,9 \%$, sẩn dẹt 3,5\%.

Màu sắc sùi mào gà: màu hồng $(94,1 \%)$, màu đỏ $(1,2 \%)$, xám trắng $(12,9 \%)$, nâu đen $(2,4 \%)$.

Vị trí thương tổn: dương vật 15,3\%, hậu môn $21,2 \%$, môi bé $60 \%$, môi lớn $52,9 \%$, thành âm đạo $16,5 \%$, các vị trí khác $11,8 \%$.

HPV týp 6 và 11 chiếm tỷ lệ cao nhất, lần lượt là $45,9 \%$ và $54,1 \%$.

Týp HPV nguy cơ thấp chiếm $18,8 \%$, nguy cơ cao chiếm $10,6 \%$ và nhiếm cả 2 nhóm týp chiếm $70,6 \%$.

Sự phối hợp nhiễm các týp HPV: 15,3\% bệnh nhân chỉ nhiểm 1 týp HPV, 48,2\% nhiễm 2 týp HPV và $36,5 \%$ nhiếm từ 3 týp HPV trở lên.

Có mối liên quan giữa nhóm týp HPV và giới tính. Ở nam có tỷ lệ nhiễm týp HPV nguy cơ cao nhiều hơn nữ.

Có mối liên quan giữa vị trí thương tổn và nhiêm nhóm týp HPV. Ở dương vật, môi bé và âm hộ có tỷ lệ nhiễm nhóm týp nguy cơ cao và cả 2 nhóm týp HPV nhiêu hơn.

Kết quả điều trị: tỷ lệ tốt $71,8 \%$, tỷ lệ tái phát $15,3 \%$, tỷ lệ tác dụng phụ $2,4 \%$, tỷ lệ biến chứng chảy máu $1,2 \%$, đau $7,1 \%$, phù nề $8,2 \%$ và nhiễm trùng là $3,5 \%$.

Không có mối liên quan giữa các nhóm týp HPV với kết quả điều trị và biến chứng sau điều trị. 


\section{BÀN LUẬN}

Theo Bùi Thi Thùy Dung (2018) [2], trong 46 bệnh nhân tham gia nghiên cứu có 40 bệnh nhân có thương tổn là sùi chiếm $87 \%$, còn lại 6 bệnh nhân có thương tổn là những sẩn chiếm $13 \%$, không có thương tổn dát. Nghiên cứu của Nguyễn Quang Minh (2010) [3] là $80,9 \%$ và nghiên cứu của F. Akpadjan, H. Adegbidi và cộng sự (2017) [5], tỷ lệ sùi là $82,4 \%$. Như vậy nghiên cứu của chúng tôi cũng gần tương tự với các tác giả trên, dạng sùi là chiếm ưu thế.

Khác với nghiên cứu của chúng tôi thì nghiên cứu của $\mathrm{F}$. Akapadjan, $\mathrm{H}$. Adegbidi và Cộng sự (2017)[5], có $6,8 \%$ thương tổn là sùi mào gà không lî̀ là một thể rất hiếm gặp do HPV6 và 11 gây nên. Bệnh có đặc điểm là xâm lấn xuống dưới trung bì. Tổ chức bệnh học có những vùng lành tính xen kẽ với các ổ tế bào thượng bì bất thường hoặc các tế bào biệt hóa ung thư tế bào gai. Các vị trí và hình thái lâm sàng của các thương tổn được quan sát thấy ở bệnh nhân của chúng tôi là phù hợp với các tài liệu chứng minh rằng sùi mào gà có thể là sùi, sẩn, thậm chí khổng lồ đặc biệt ở người suy giảm miễn dịch.

Trong nghiên cứu của chúng tôi, trên số phần trăm nhiễm HPV thì týp 6 và týp 11 chiếm tỷ lệ cao nhất lần lượt là $45,9 \%$ và $51,1 \%$. Theo nghiên cứu của Ingles (2015) [6], trong các loại HPV nguy cơ thấp thì týp 6 và týp 11 chiếm tỷ lệ cao nhất lần lượt là $49,4 \%$ và $31,0 \%$. Như vậy, nghiên cứu của chúng tôi cũng tương đồng với các nghiên cứu khác, cho thấy vai trò của HPV6 và HPV11 trong vai trò phát triển của sùi mào gà. Trong nghiên cứu của chúng tôi, số người nhiễm HPV nguy cơ thấp chiếm $18,8 \%$, tỳ lệ nhiễm nhóm týp HPV nguy cơ cao là $10,6 \%$ và nhiễm cả 2 nhóm là 70,6\%. Theo nghiên cứu của Nowak, R. G. (2020) [8] thì tỷ lệ nhiếm HPV nguy cơ cao chiếm tỷ lệ $74 \%$. Nghiên cứu của chúng tôi có $15,3 \%$ bệnh nhân chỉ nhiễm 1 týp HPV, có $48,2 \%$ bệnh nhân nhiễm 2 týp HPV và 36,5\% bệnh nhân nhiễm từ 3 týp HPV trở lên. Như vậy, nghiên cứu của chúng tôi khác với các nghiên cứu trước về sự nhiễm nhóm týp HPV và sự phối hợp nhiễm các týp HPV trên một bệnh nhân. Điều này có thể giải thích do vùng địa lý khác nhau, cõ̃ mẫu nghiên cứu khác nhau và có thể do lối sống tình dục, bạn tình của các đối tượng khác nhau.

Nghiên cứu của chúng tôi, có $87,1 \%$ bệnh nhân được điều trị bằng laser $\mathrm{CO} 2,12,9 \%$ bệnh nhân được điều trị bằng phẫu thuật. Điều trị sùi mào gà đạt kết quả tốt chiếm tỷ lệ $71,8 \%$, tái phát chiếm $15,3 \%$ và có tác dụng phụ là $2,4 \%$.
Tỷ lệ bệnh nhân điều trị sùi mào gà có biến chứng chảy máu là $1,2 \%$, nhiễm trùng là $3,5 \%$, đau là $7,1 \%$ và phù nề là $8,2 \%$. Theo nghiên cứu của Nguyễn Quý Thái (2011)[4], kết quả điều trị tốt chiếm $70,05 \%$, tái phát chiếm $17,1 \%$, tác dụng phụ là $2,63 \%$. Biến chứng chảy máu $1,31 \%$, đau rát $3,94 \%$, sưng nề $6,58 \%$. Theo Mehdi và cộng sự (2019)[7], khoảng 20\% bệnh nhân có đau nhẹ sau khi làm phẫu thuật, nhưng họ có thể chịu đựng được. Tỷ lệ tái phát sau 3 tháng được ghi nhận trong nghiên cứu là $2 / 15$ bệnh nhân $(13,3 \%)$. Như vậy kết quả điều trị tốt cũng như tỷ lệ tái phát và tác dụng phụ của chúng tôi gần tương đương với các tác giả khác, tỷ lệ các biến chứng cũ̃ng gần tương đương. Tuy nhiển, biến chứng nhiễm trùng trong nghiên cứu của chúng tôi cao hon các nghiên cứu trước do đa phần biến chứng này sử dụng ở bệnh nhân phẫu thuật: sự tác động của phâu thuật gây thương tổn lớn, bệnh nhân chăm sóc không được vệ sinh do vùng điều trị đa phần ở bộ phận sinh dục (môi bé, môi lớn, hậu môn) là vùng ẩm ướt, dể nhiễm trùng. Tuy nhiên nhìn chung, tỷ lệ bệnh nhân có biến chứng trong nghiên cứu của chúng tôi thấp hơn các nghiên cứu khác. Điều này có thể được giải thích do tay nghề và các kỹ thuật của các bác sĩ được nâng cao.

\section{KẾT LUÂN}

Qua kết quả nghiên cứu 85 bệnh nhân sùi mào gà trong thời gian từ tháng $5 / 2020$ đến tháng 11/2020 tại Bệnh viện Da liều Thành phô Cần Thơ. Một số kết luận được rút ra như sau: Trong kỹ thuật thực hiện điều trị, để hạn chế biến chứng đau, phù nề cần có biện pháp vô cảm tốt, đặc biệt ở các vị trí như thành âm đạo, cổ tử cung; Điều trị sùi mào gà bằng laser $\mathrm{CO} 2$ và phẫu thuật là phương pháp an toàn và hiệu quả, có tỷ lệ tái phát, tỷ lệ tai biến và biến chứng thấp. Nên tiếp tục sử dụng các phương pháp này trong điều trị bệnh sùi mào gà; ở dương vật, môi bé và âm hộ có tỷ lệ nhiễm týp HPV nguy cơ cao nhiều hơn các vị trí còn lại. Do đó, những vị trí này khi bị sùi mào gà cần được theo dõi và tầm soát về khả năng gây ung thư của HPV.

\section{TÀI LIÊU THAM KHẢO}

1. Hà Nguyên Phương Anh (2015), Nhiễm Human Papillomavirus trên bệnh nhân bị nhiếm trùng lây truyên qua đường tình dục và tác dụng của cimetidin trong phòng tái phát bênh sùi mào gà, Luận án Tiến sĩ y học, Trường Đại học Y Hà Nội.

2. Bùi Thị Thùy Dung (2018), Nghiên cứu đặc điểm lâm sàng, tìm hiểu một số yếu tố liên quạn và đánh giá kết quả điều trị bệnh sùi mào gà̀ bằng phương pháp đốt điện tại Bệnh viện Da liễu Cần 
Thơ năm 2017-2018, Luận văn tốt nghiệp Đại học, Trường Đai hoc Y Dược Cần Thơ.

3. Nguyển Quang Minh (2010), "Đặc điểm lâm sàng và các yếu tố liên quan đến bệnh sùi mào gà", Tạp chí Da liễu hoc Việt Nam. 10, tr. 31-35.

4. Nguyển Qúy Thái (2011), "Đánh giá hiệu quả điểu trị sùi mào gà sinh dục bằng phẩu thuật Laser CO2 tại Thành phố Thái Nguyên", Tạp chí Y học thức hành. 6 , tr. 111-114.

5. Akpadjan, F, et al. (2017), "Anogenital Condyloma: Epidemiological, Clinical, Therapeutic and Evolutionary Aspects of 74 Cases in Benin", Journal of Cosmetics, Dermatological Sciences and
Applications. 7(3), pp. 221-228.

6. Ingles, Donna J., et al. (2015), "Human papillomavirus virus (HPV) genotype- and age-specific analyses of external genital lesions among men in the HPV Infection in Men (HIM) Study", The Journal of infectious diseases. 211(7), pp. 1060-1067.

7. Mehdi, Mayyadah $H$ and Mahmood, Ali $S$ (2019), "Treatment of genital warts by using $\mathrm{CO} 2$ laser", Medical Journal of Babylon. 16(2), pp. 94-98.

8. Nowak, R. G., et al. (2020), "Multiple HPV infections among men who have sex with men engaged in anal cancer screening in Abuja, Nigeria", Papillomavirus Res. 10, p. 100-200.

\section{HIỆU QUẢ ĐIỀU TRI MẤT NGỦ KHÔNG THỰC TỔN THỂ TÂM TỲ HƯ BẰNG PHƯƠ'NG PHÁP CẤY CHİ KẾT HỢP TÂPP DƯỡNG SINH}

\section{TÓM TẮT}

Mục tiêu: Đánh giá hiệu quả điều trị mất ngủ không thực tổn thể tâm tỳ hửbằng cây chỉ kết hợp tập dưỡng sinh. Đối tượng và phương pháp: Nghiên cứu tiến cứu, so sánh kết quả trước và sau điều trị có đối chứng.60 bệnh nhân tuổi trên 18 được chẩn đoán mất ngủ không thực tổn, phù hợp chứng thất miên thể tâm tỳ hư theo $Y$ học cổ truyền, không phân biệt giới tính, nghề nghiệp, tình nguyện tham gia nghiên cứuđược phân thành hai nhóm, nhóm nghiên cứu điều trị bằng cấy chỉ kết hợp tập dưỡng sinh x 30 ngày, nhóm đối chứng điều trị bằng uống Rotundavới thời gian tương tự. Kết quả:Thời gian vào giấc ngủ, tần suất rối loan giấc ngủ ở nhóm nghiên cứu cải thiên rõ rệt so với trước điều trị. Chất lượng giấc ngủ đánh giá ở mức tốt đạt $55,7 \%$, thời lượng giấc ngủ trung bình

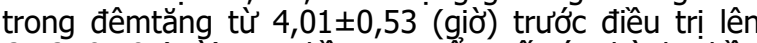
$6,76 \pm 0,40$ (giờ) sau điêuu trị. Điểm số các thành phân PSQI sau điểu trị cải thiện có ý nghĩa thống kê so với trước điều trị và tốt hơn nhóm đối chứng. Tổng điểm PSQI trung bình giảm từ 13,97 $\pm 3,01$ trước điều trị

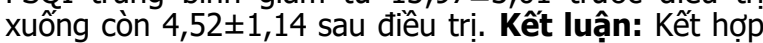
giữa cấy chỉ và tập dưỡng sinh là phương pháp điều trị hiêu quả tình trang mất ngủ không thực tổn.

Tư khóa: Mất ngủ, cây chỉ,dưỡng sinh.

\section{SUMMARY}

\section{EFFECT OF ACUPOINT CATYGUT EMBEDDING THERAPY COMBINED WITH HEALTH PRESERVING IN THE TREATMENT FOR NONORGANIC INSOMNIA}

Objectives: Reseach is done aiming to evaluate the efficacy of acupoint catgut embedding therapy

\footnotetext{
${ }^{1}$ Bệnh viện Châm cứu Trung ương,

${ }^{2}$ Viên Y hoc cổ truyền Quân đồi

Chịu trách nhiệm chính: Nguyễn Đức Minh

Email: Email: drminhchamcuu@gmail.com

Ngày nhận bài: 29/7/2021

Ngày phản biên khoa hoc: 28/8/2021

Ngày duyệt bài: 19/9/2021
}

\section{Nguyễn Đức Minh ${ }^{1}$, Nguyễn Vinh Quốc ${ }^{2}$}

combined with health preserving in the treatment for nonorganic insomnia. Subjects and methods: A prospective controlled clinical trial and comparing results before and after treatment. 60 cases aged over 18 , being diagnosed with insomnia disorder,consistent with Xinpixushimian by traditional medicine, regardless of gender, occupation, volunteer for research were divided into two groups. The study group was treated by combination of acupoint catgut embedding therapy and health preserving $\times 30$ days and the control group was drunk by Rotunda with the same duration. Results: The duration of sleep and the frequency of sleep disturbances in the research group improved significantly compared to before treatment. The quality of sleep assessed at a good level reached $55.7 \%$, the average sleep duration during the night increased from $4.01 \pm 0.53$ (hours) before treatment to $6.76 \pm 0.40$ (hour) after treatment. The score of PSQI components after treatment improved statistically significantly compared to before treatment and better than the control group. Mean total PSQI score decreased from $13.97 \pm 3.01$ before treatment to $4.52 \pm 1.14$ after treatment. Conclusion: The combination ofacupoint catgut embedding therapy and health preservingwas an effective treatment for nonorganic insomnia.

Key words: Acupoint catgut embedding, health preserving, nonorganic insomnia.

\section{I. ĐẶT VẤN ĐỀ}

Rối loạn giấc ngủ là trạng thái không thoải mái về số lượng và chất lượng của giấc ngủ do nhiêuu nguyên nhân khác nhau gây nên [1]. Tại Việt Nam, rối loạn giấc ngủ chiếm tỷ lệ cao (50$80 \%$ ) và là nguyên nhân gây ra các rối loạn trâm cảm, rối loạn lo âu và các bệnh lý tâm sinh [1]. Mất ngủ không thực tổn, một dạng của rối loạn giấc ngủ hiện đang là vấn đề được các nhà nghiên cứu trên thế giới cũng như trong nước và cộng đồng xã hội quan tâm đặc biệt vì nó ảnh hưởng trực tiếp đến sức khỏe, chất lượng cuộc 